\title{
The Double Burden of Malnutrition in Countries Passing through the Economic Transition
}

\author{
Andrew M. Prentice \\ MRC Unit The Gambia at LSHTM, Banjul, The Gambia; London School of Hygiene \& Tropical Medicine, London, UK
}

\section{Key Messages}

- Most low- and middle-income countries that manage to avoid conflict are undergoing economic advancement to a greater or lesser degree.

- The prevalence of undernutrition is strongly correlated with a country's wealth and hence stunting and underweight tend to disappear as wealth advances. This is the good news.

- The bad news, which should be of great concern to the governments of emerging nations, is that economic advancement seems inevitably associated with a rapidly increasing prevalence of obesity. Without urgent actions to combat these trends, countries will be faced with ever-growing health costs as they try to cope with the obesity-related chronic diseases, especially diabetes.

\section{Keywords}

Malnutrition · Obesity · Double burden dernutrition decline. Many countries successfully achieved the Millennium Development Goal of halving undernutrition and whole continents have been transformed in recent decades. The exception is Africa where the slower rates of decline in the prevalence of undernutrition has been overtaken by population growth so that the absolute number of stunted children is rising. In many regions, economic transition is causing a rapid increase in the number of overweight and obese people. The rapidity of this rise is such that many nations bear the simultaneous burdens of under- and overnutrition; termed the "double burden" of malnutrition. This double burden, accompanied as it is by the unfinished agenda of high levels of infectious diseases, is crippling the health systems of many LMICs and thus requires urgent attention. Although the prognosis looks threatening for many poor countries, they have the advantage of being able to learn from the mistakes made by other nations that have passed through the transition before them. Concerted action across many arms of government would achieve huge future dividends in health and wealth for any nations that can grasp the challenge.

(c) 2018 S. Karger AG, Basel

\section{Introduction}

The 2017 UNICEF-led report on the State of Food Security and Nutrition in the World contains both good news and bad news [1]. The good news is that the number of undernourished people in the world has declined since

\section{KARGER}

(c) 2018 S. Karger AG, Basel

E-Mail karger@karger.com

www.karger.com/anm
Andrew M. Prentice, PhD, FMedSci

MRC Unit The Gambia at LSHTM

Atlantic Boulevard, Fajara

Banjul (The Gambia)

E-Mail aprentice@mrc.gm 
Fig. 1. The number of undernourished people in the world has been falling since 2000, but may be rising again. Reproduced with permission from [1].
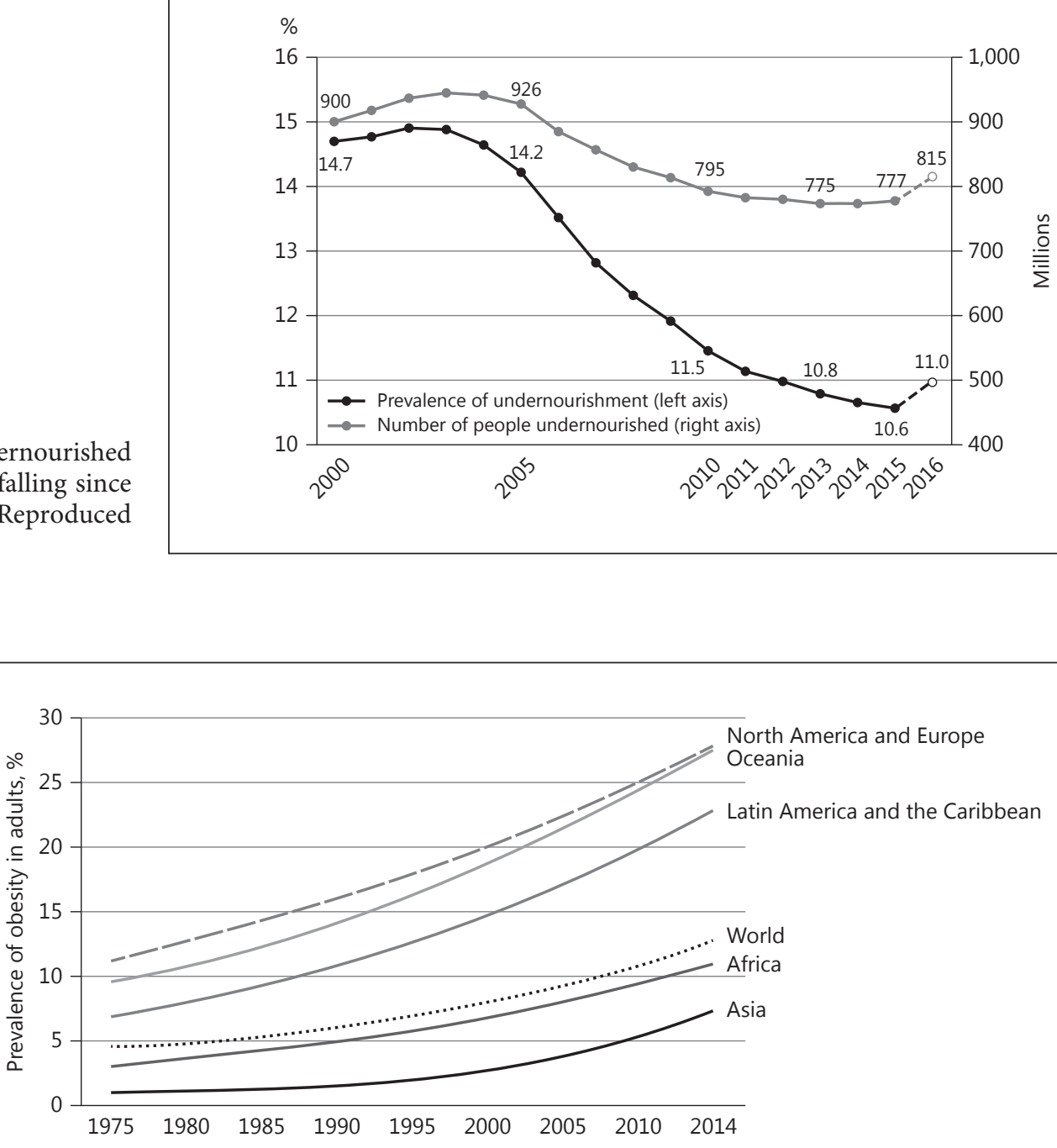

Fig. 2. Adult obesity is rising everywhere at an accelerating pace. Reproduced with permission from [1].

the early 2000s (Fig. 1). Sadly, even this good news is tinged with bad; the decline was less than $20 \%$ and the very latest data suggests that the decline halted in 2015 and has now reversed. The other bad news is that rates of obesity have been climbing steadily over the past 40 years and that this rise affects all continents (Fig. 2). In Asia, which started with the lowest prevalence of obesity and still has the best statistics, there is nonetheless some evidence that the rate of increase is accelerating.

It is this coexistence of malnutrition at each end of the spectrum that is termed the "double burden" of malnutrition. It represents a major challenge for emerging nations as their governments try to meet the health costs of caring for both conditions simultaneously [2]. This paper will discuss some of the basic etiological drivers and then use some country and regional case studies to try to capture some of the key drivers of the double burden and learn lessons for the future.

\section{Undernutrition: The Basic Drivers}

Undernutrition is classically defined by a body mass index (BMI) of less than $18.5 \mathrm{~kg} / \mathrm{m}^{2}$ in adults, and by 3 metrics in children (weight-for-age, WfA; height-for-age, HfA; and weight-for-height, WfH). In children, values less than $-2 Z$-scores compared to the WHO Anthrops 


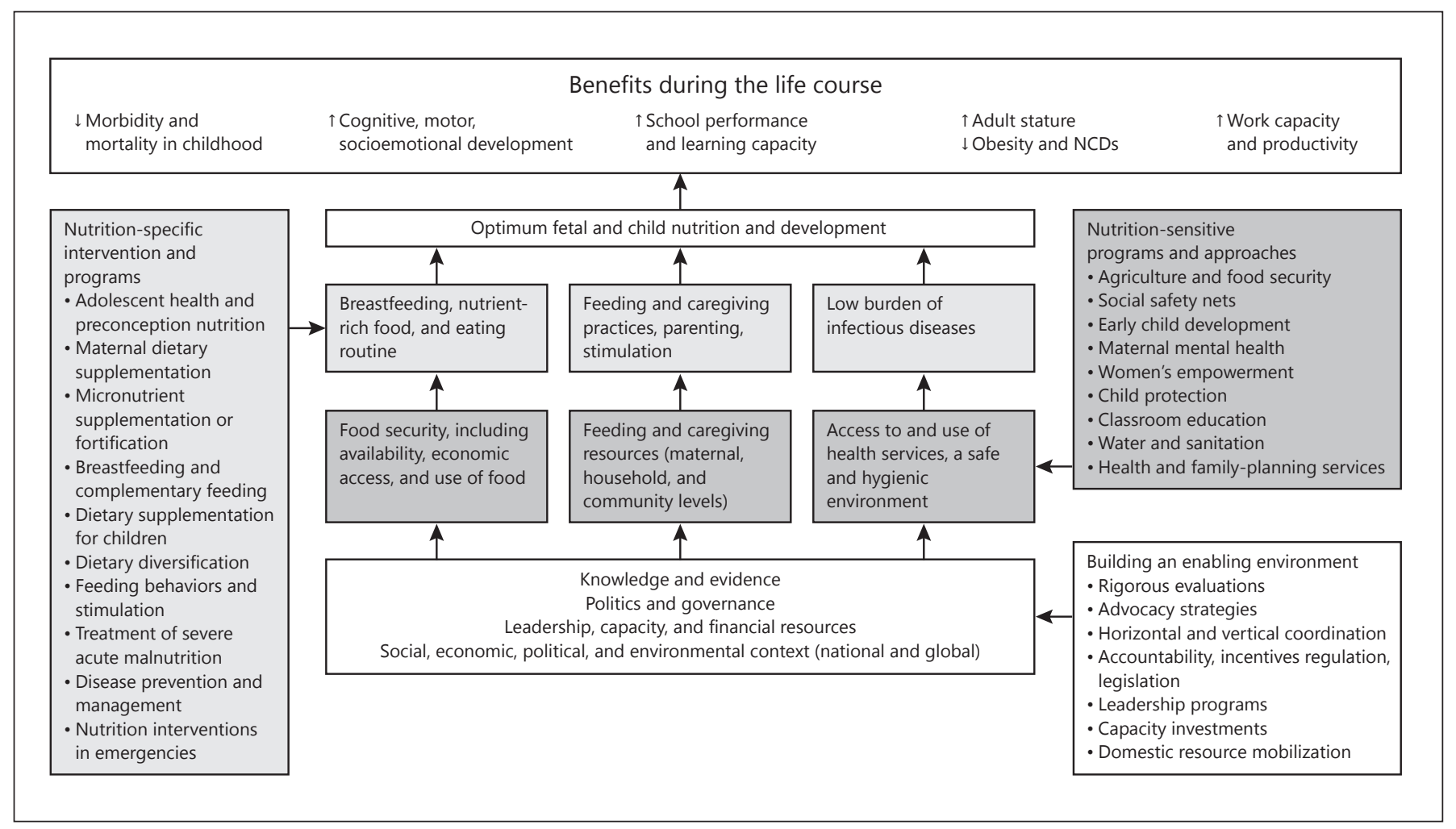

Fig. 3. Malnutrition often has many immediate and underlying causes and requires investments in solutions across many domains. Reproduced with permission from [2].

reference values are respectively defined as underweight, stunted, or wasted. Wasting is a measure of acute malnutrition and stunting of longer-term chronic malnutrition.

It goes without saying that the primary drivers of undernutrition are all associated with poverty, which in turn tends to be associated with low levels of education, especially among girls who become the primary caregivers of children. This simplistic analysis conceals many complexities both in causation and in necessary interventions that are summarized in Figure 3 from the seminal Lancet series on Maternal and Child Undernutrition and Overweight in Developing Countries [3].

Figure 4 illustrates the very strong association between a country's level of wealth and stunting rates. Stunting is rare in wealthy nations and where it does occur it is likely driven by a specific pathology within the child or to be confined to recent or second-generation immigrants who have yet to escape from the long-term intergenerational consequences in their parents' and possibly grandparents' undernourishment. It is notable that there is wide diversity between stunting levels among the poorer coun- tries on the left-hand side of Figure 4. This emphasizes how progress against malnutrition can be achieved even in the poorest nations.

\section{Nutrition-Specific and Nutrition-Sensitive Causes of Undernutrition}

There is an increasing awareness that a child's nutritional status in not determined by dietary and nutritional factors alone. These operate within a constellation of other environmental influences that can impact their growth and health. For instance, a child's energy and nutrient status is determined by the cumulative balance between its intake and its utilization or losses. In young children, whose immature immune systems have to learn to cope with the many infectious and antigenic threats that surround them in unhygienic environments, the role of infections is thought to be paramount. This explains why early postnatal growth falls so far below the WHO reference curves in the first 2 years of life, as illustrated in Figure 5 for children in rural Gambia. The pattern shown in 


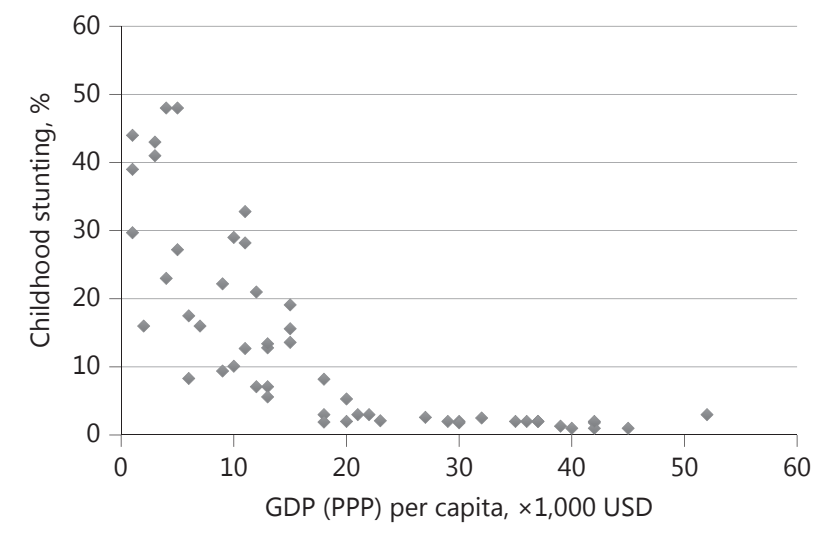

Fig. 4. Stunting rates as a function of countries' per capita gross domestic product (GDP). Stunting statistics (age $0-5$ years) use the latest data available for each country (limited to countries with post-2000 data) from WHO's Global Database on Child Growth and Malnutrition (http://www.who.int/nutgrowthdb/database/ countries/en/index.html). Per capita GDP adjusted for purchasing power parity (PPP) mostly refer to 2012 and were accessed from the International Monetary Fund's (IMF) World Economic Outlook Database, October 2013.

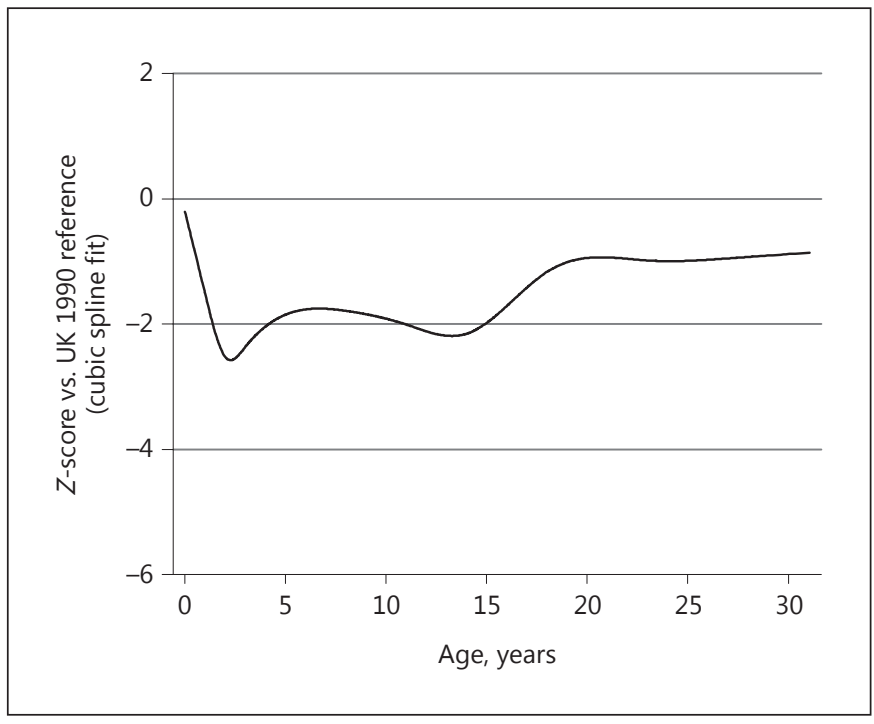

Fig. 5. Height growth in rural Gambian children. The line illustrates the median height-for-age Z-score (against the UK 1990 growth centiles) from over 50,000 individual measurements.
Figure 5 is replicated in all low-income settings as shown by Victora et al. [4] in their renowned meta-analysis of data from 54 low- and middle-income countries (LMICs) that formed the basis of the "first 1,000 days" concept. It is notable, at least in our Gambian data, that the children's nutritional status stops deteriorating at about 2 years of age and starts a partial recovery. The effects of the infections are thought to arise from the excess nutrient and energy drain needed to mount an immune response (especially the adaptive responses), from children's loss of appetite when sick and from malabsorption secondary to the condition of so-called environmental enteric disease, which is a chronic damage and persistent inflammation of the gut.

This strong link with early childhood infections and environmental enteric disease suggests that improved water, sanitation, and hygiene (WASH) should have a big impact on such outcomes, and large investments have been made to test this hypothesis. The largest trials have been the WASH Benefits trials in Bangaldesh and Kenya [5] and the SHINE trial in Zimbabwe [6]. The SHINE results are not yet fully published in peer-reviewed journals, but have been presented at meetings. The WASH Benefits results have been published recently $[7,8]$. The trial arms that included improved infant and young child feeding (IYCF) advice showed evidence of improvements in growth, but the effect sizes were very small. Disappointingly, the WASH arms achieved no benefit. A possible interpretation of this is not that the concept is faulty but rather that the interventions were not nearly intensive enough. They improved latrines and educated mothers about hygiene and provided washing stands and soap, but they did not truly re-engineer the environment to give families the wherewithal to make substantive differences to their children's exposure to dirt and pathogens.

\section{The Emergence of Overweight and Obesity Worldwide}

Prior to the 1970 s, obesity was a relatively rare condition even in the wealthiest of nations, and when it did exist it tended to occur among the wealthy. Then, a confluence of events started to change the human condition. The average BMI of populations in first-world countries started to increase and, consequently, there was a raid increase in the proportion of people overweight and obese. Serial state-by-state surveys in the USA from the 1980s onwards describe a remarkable transformation and associated surveys of diabetes show delayed but otherwise highly correlated trends. These data can be accessed and 


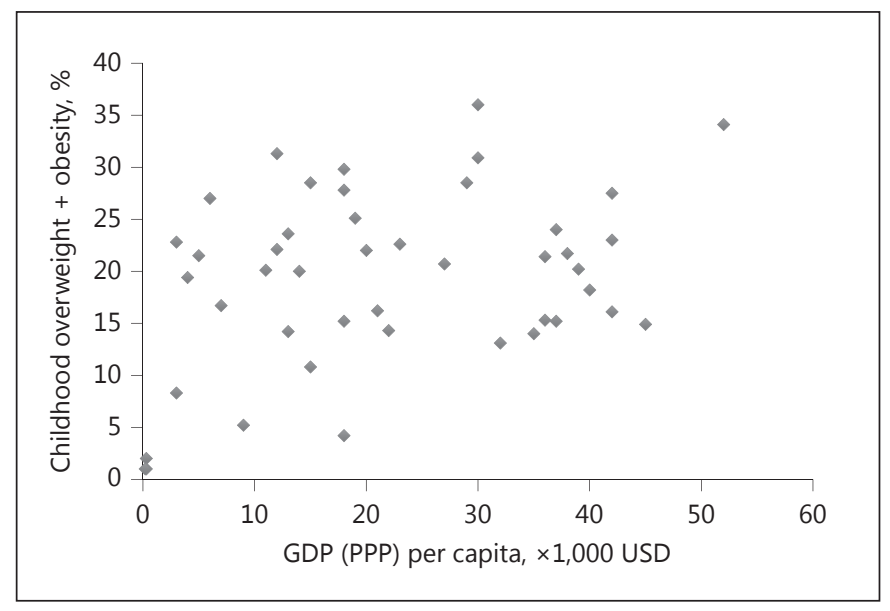

Fig. 6. Childhood overweight and obesity rates as a function of countries' per capita gross domestic product (GDP). Overweight and obesity statistics use the latest data available for each country (limited to countries with post 2000 data) collated by the International Obesity Taskforce (http://www.iaso.org/iotf/obesity/? map $=$ children). GDP adjusted for purchasing power parity (PPP) mostly refer to 2012 and were accessed from the International Monetary Fund's (IMF) World Economic Outlook Database, October 2013.

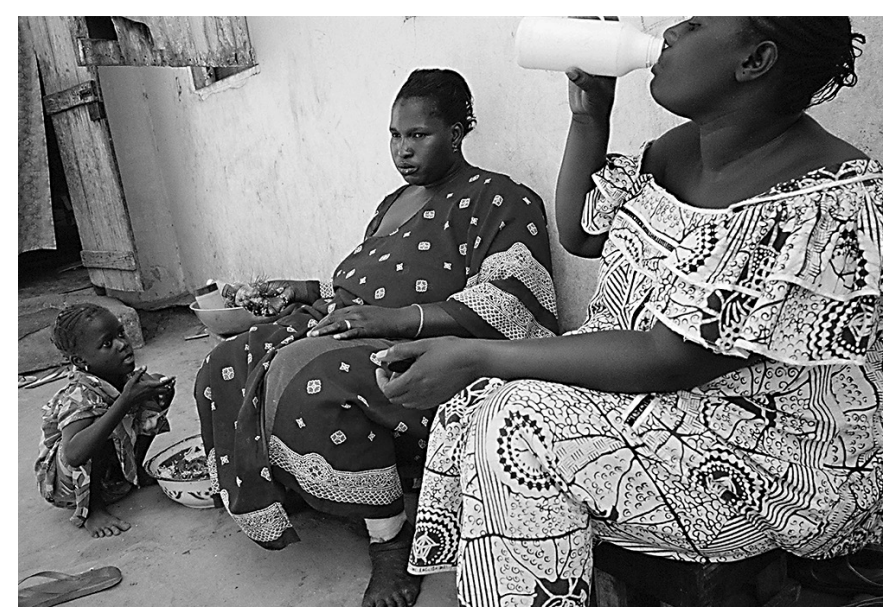

Fig. 8. Obesity is now a common sight in urban areas of Africa, especially among middle-aged women. Photo credit: Felicia Webb.

downloaded from the Centers for Disease Control (CDC) website (www.cdc.gov).

Figure 6 shows that, unsurprisingly, the relationship between obesity (in this case plotted as childhood overweight and obesity) and country wealth is reciprocal to that for undernutrition shown in Figure 4. As noted for

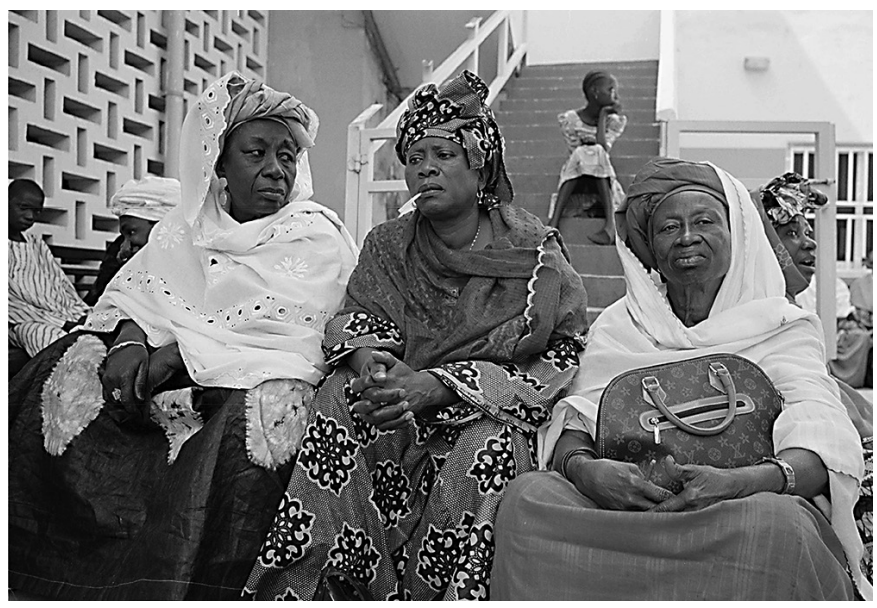

Fig. 7. Overweight and obese patients queue for a diabetic clinic. Photo credit: Felicia Webb.

the undernutrition statistics, there is a notable spread of prevalence rates among countries with similar levels of wealth. This partly reflects the fact that some countries have undergone very rapid economic improvements and their (predictably rising) obesity rates have not yet caught up, but it also captures true differences that may be related to national behaviors and health policies. For instance, a country such as the Netherlands with, among other things very high rates of cycling which are encouraged by cycle-friendly policies, has consistently lower obesity rates than neighboring countries such as the UK.

The factors leading to the obesity pandemic were several and complex. Food prices declined as a proportion of peoples' disposable income and the energy density of foods increased rapidly as foods were subjected to higher rates of extraction and refinement. An analysis of these trends in the UK demonstrated that such changes did not seem to greatly increase average per capita food intake, and thus an alternative (or additional) explanation was required. The same analysis showed that sedentary lifestyles and the associated reduction in energy expenditure probably played (and still plays) a major role [9]. Genetic effects cannot explain these rapid population shifts in obesity, though they can help to explain which individuals within any given population will be more or less susceptible. Recent research has revealed that epigenetic effects may explain a much greater proportion of population variance than genetic effects [10, $11]$ and this has implications for prevention as discussed below. 
Fig. 9. Male-female and urban-rural differences in overweight and obesity rates in The Gambia. Reproduced from Prentice [2] with permission.

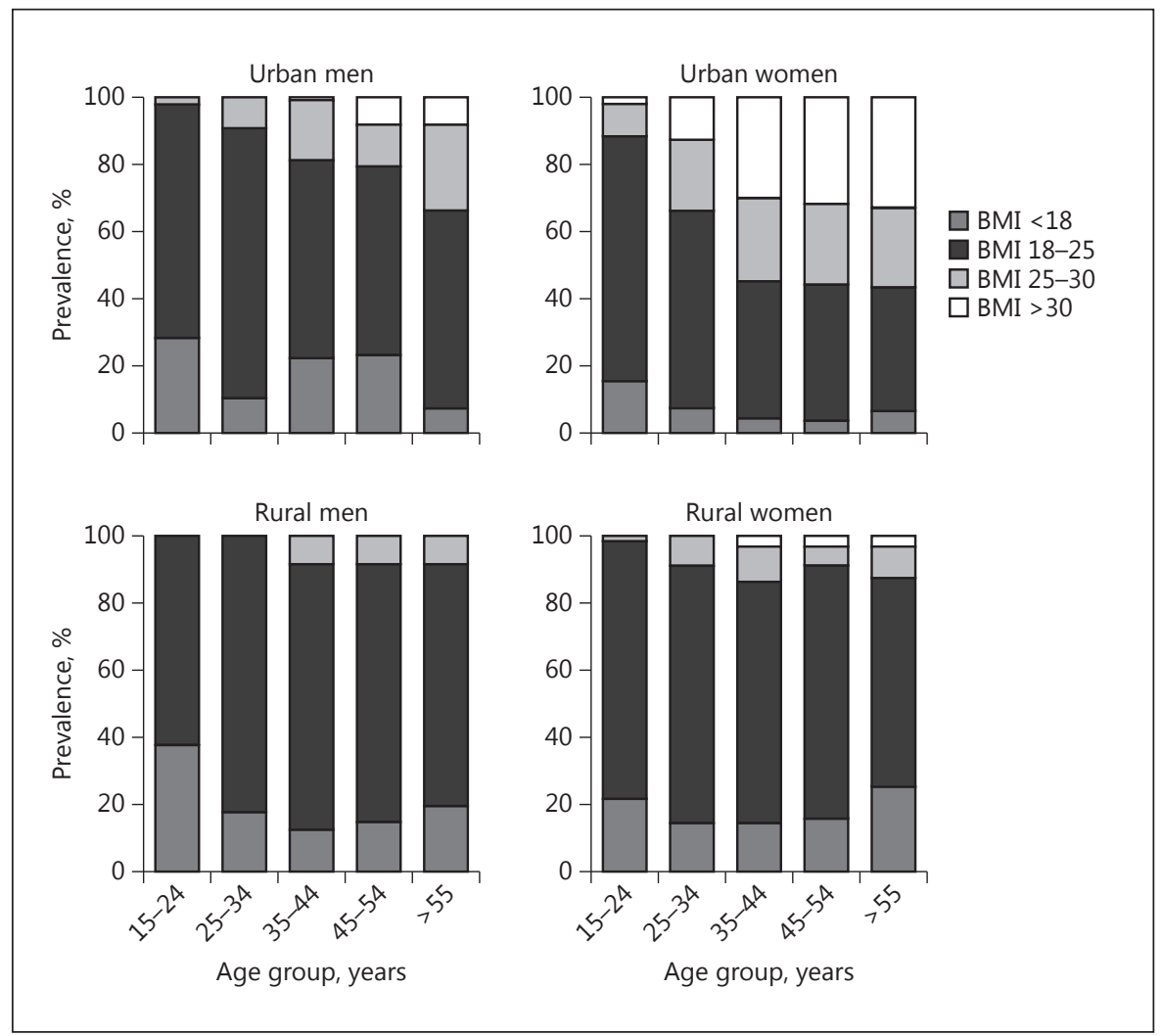

\section{The Demographic Switch in Social Groups Most Susceptible to Obesity}

In poorer nations, it is generally only the rich who can, and do, become obese, but as nations pass through the demographic transition a switch occurs and the wealthier strata tend to be less likely to be obese and the poorer strata more likely. The photographs in Figures 7 and 8 show relatively wealthy women waiting for their appointments at the diabetes clinic and yet poorer women similarly afflicted; this is from a country in which the switch is in the process of playing out.

Within many poor countries, especially in Africa, there are 2 notable features of obesity distribution as illustrated in Figure 9 for The Gambia [2, 12]. First, there tends to be a strong urban-rural gradient with much more obesity in townships and cities. Second, within those urban areas, women are often much more likely to be obese than men (see the white and light-grey areas at the top right hand of Fig. 9). There are deep social reasons for such trends [13] and an understanding of them is important in designing interventions.

The pace of the demographic transition is such that in some regions of the world it is not uncommon to see stunted children living in households where one or both of their parents (usually the mother) is clinically obese [e.g., 14].

\section{National Challenges Posed by the "Double Burden" of Malnutrition}

The poor and emerging nations of the world are, by definition, the least able to bear the health costs of treating serious nutrition-related conditions such as severe acute malnutrition and obesity-related diabetes. As a consequence, treatment facilities are often poorly equipped and staffed, and hence the case fatality rates for such conditions are much higher than in rich nations. The photographs in Figures 10 and 11 were taken on the same day in a tertiary level hospital in urban Africa. The bed-ridden woman was awaiting amputation of her diabetic foot (reported by the surgeons as one of the most common operations they performed). The malnourished child was in a ward directly below the adult ward, graphically illustrating the juxtaposition of the two extremes of malnutrition and the terrible challenges that this poses. When considered in the context of the high additional 


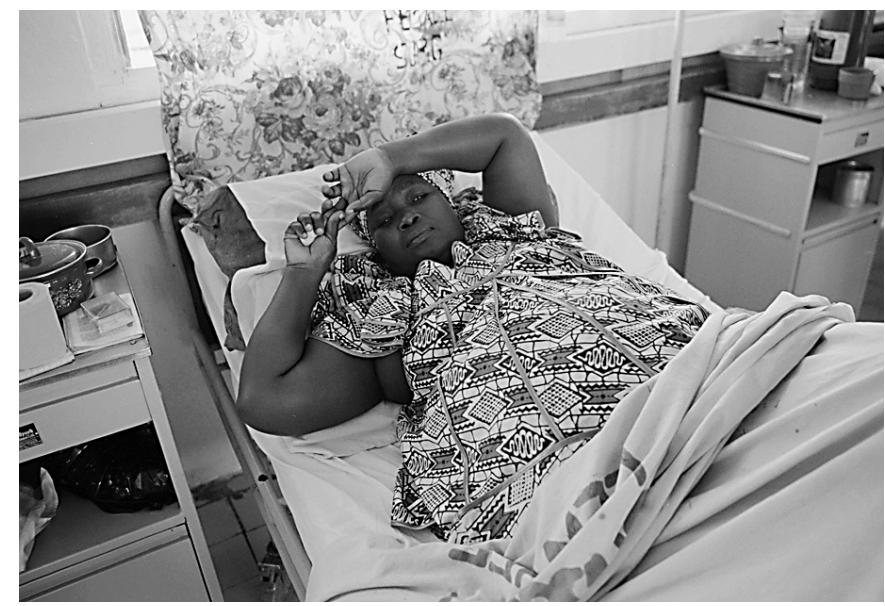

Fig. 10. An overweight patient awaits treatment for her diabetic foot. Photo credit: Felicia Webb.

burden of treating infectious diseases, it is no wonder that so many health systems are failing. A visit to such hospitals can be a traumatic experience for visitors used to topquality first-world medical care.

\section{Solutions}

A decade ago, the UK government published the seminal Foresight Report [15] that attempted to collate all the available evidence about the drivers of the obesity epidemic and to use this knowledge to construct recommendations for government action. The report acknowledged that the metabolic mechanisms regulating (or failing to regulate) energy balance in humans were central to all efforts, but that these were influenced by a wide variety of social and environmental determinants that were rapidly changing in our modern world. They drew up a complex "systems map" to describe these influences and used it to press the case that strategies against obesity must be developed by almost every government department from health to transport, housing, education, and sport, and all must have the support of treasury. Though developed for the UK, these lessons are applicable everywhere.

The World Health Organization has convened expert groups on obesity and noncommunicable diseases and is constantly updating the evidence base used to plan recommended initiatives [e.g., 16, 17]. These are backed by ancillary reports on mechanisms to achieve these ends such as fiscal measures against sugary drinks [18] and development of a global action plan to promote physical activity [19]. The

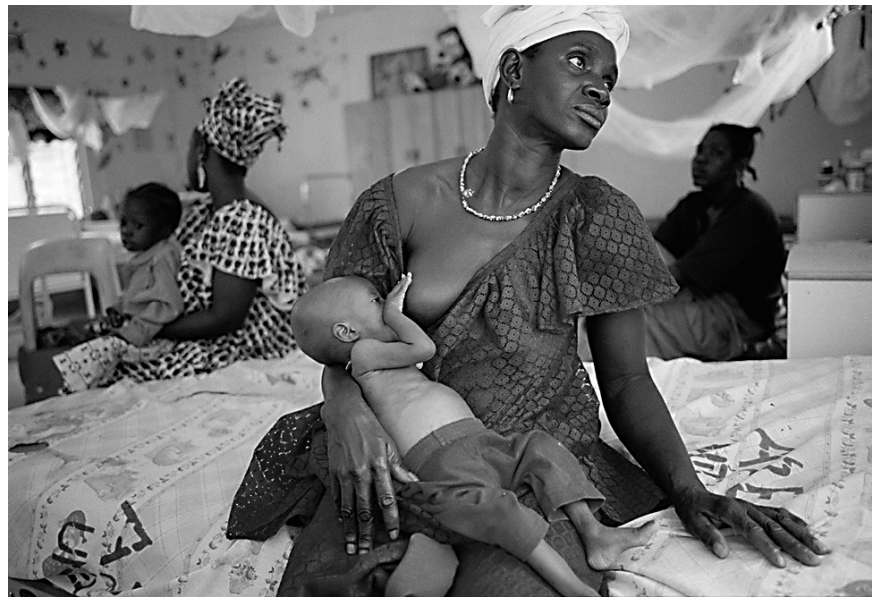

Fig. 11. A malnourished child in a nearby ward exemplifies the health system's challenges of the double burden of malnutrition. Photo credit: Felicia Webb.

report on childhood obesity makes a large number of recommendations [17], indeed probably an overwhelming number for low-income countries that already have major challenges in strengthening their school systems.

A relatively new element of all of these efforts is the recent appreciation of how important it is to consider both ends of the malnutrition spectrum with a life-course lens. In other words, to understand that childhood undernutrition has prenatal and probably intergenerational origins $[11,17]$. Most children who are stunted at the age of 2 years were already stunted at birth [19] and were born to small mothers. Likewise, a malnourished fetus may adopt a "thrifty phenotype" [20] that is better able to accrue fat in later life if exposed to an obesogenic environment and is therefore at special risk of inappropriate weight gain.

\section{Prospectus for the Future}

The economic advancement and associated demographic transitions that are happening in most countries except those marred by conflict will ultimately bring a natural decline in undernutrition. Progress in recent decades has been good in all continents except Africa as a whole; and even here there were many nations that achieved their Millennium Development Goal of halving malnutrition. However, unless the governments and peoples of these emerging nations are able to learn lessons from the countries that have passed through the transition before them, they will incur a huge burden of overweight and obesity. The challenge therefore is first to recognize the impending 
threat and then to take cross-government actions to halt the epidemic and its associated health crisis. The greatest hope lies in the fact that most governments are at least aware of the threat; finding the bandwidth and resources to tackle it would bring long-term gains in health and wealth to any government that can achieve it.

\section{Disclosure Statement}

The writing of this article was supported by Nestlé Nutrition Institute.

\section{References}

1 FAO, IFAD, UNICEF, WFP, WHO: The State of Food Security and Nutrition in the World 2017. Building Resilience for Peace and Food Security. Rome, FAO, 2017.

2 Prentice AM: The emerging epidemic of obesity in developing countries. Int J Epidemiol 2006;35:93-99.

3 Black RE, Victora CG, Walker SP, et al: Maternal and child undernutrition and overweight in low-income and middle-income countries. Lancet 2013;382:427-451.

4 Victora CG, De Onis M, Hallal PC, et al: Worldwide timing of growth faltering: revisiting implications interventions. Pediatrics 2010;125:e473-e480.

5 Arnold BF, Null C, Luby SP, et al. Clusterrandomised controlled trials of individual and combined water, sanitation, hygiene and nutritional interventions in rural Bangladesh and Kenya: the WASH Benefits study design and rationale. BMJ Open 2013;3:e003476.

6 Sanitation Hygiene Infant Nutrition Efficacy (SHINE) Trial Team, Humphrey JH, Jones AD, Manges A, Mangwadu G, Maluccio JA, Mbuya MN, Moulton LH, Ntozini R, Prendergast AJ, Stoltzfus RJ, Tielsch JM: The Sanitation Hygiene Infant Nutrition Efficacy (SHINE) trial: rationale, design, and methods. Clin Infect Dis 2015;61(suppl 7):S685S702.

7 Null C, Stewart CP, Pickering AJ, Dentz HN, Arnold BF, Arnold CD, Benjamin-Chung J, Clasen T, Dewey KG, Fernald LCH, Hubbard AE, Kariger P, Lin A, Luby SP, Mertens A, Njenga SM, Nyambane G, Ram PK, Colford
JM Jr: Effects of water quality, sanitation, handwashing, and nutritional interventions on diarrhoea and child growth in rural Kenya: a cluster-randomised controlled trial. Lancet Glob Health 2018;6:e316-e329.

8 Luby SP, Rahman M, Arnold BF, Unicomb L, Ashraf S, Winch PJ, Stewart CP, Begum F, Hussain F, Benjamin-Chung J, Leontsini E, Naser AM, Parvez SM, Hubbard AE, Lin A, Nizame FA, Jannat K, Ercumen A, Ram PK, Das KK, Abedin J, Clasen TF, Dewey KG, Fernald LC, Null C, Ahmed T, Colford JM Jr: Effects of water quality, sanitation, handwashing, and nutritional interventions on diarrhoea and child growth in rural Bangladesh: a cluster randomised controlled trial. Lancet Glob Health 2018;6:e302-e315.

9 Prentice AM, Jebb SA: Obesity in Britain: gluttony or sloth? BMJ 1995;311:437-439.

10 Kühnen P, Handke D, Waterland RA, et al: Interindividual variation in DNA methylation at a putative POMC metastable epiallele is associated with obesity. Cell Metab 2016;24: 502-509.

11 Fleming TP, Watkins A, Velazquez MA, et al: Origins of lifetime health around the time of conception: causes and consequences. Lancet, in press.

12 van der Sande MA, Ceesay SM, Milligan PJ, et al: Obesity and undernutrition and cardiovascular risk factors in rural and urban Gambian communities. Am J Public Health 2001;91: 1641-1644

13 Siervo M, Grey P, Nyan OA, Prentice AM: A pilot study on body image, attractiveness and body size in Gambians living in an urban community. Eat Weight Disord 2006;11:100109.

14 Kimani-Murage EW, Muthuri SK, Oti SO, Mutua MK, van de Vijver S, Kyobutungi C: Evidence of a double burden of malnutrition in urban poor settings in Nairobi, Kenya. PLoS One 2015;10:e0129943.

15 World Health Organization: Global Action Plan for the Prevention and Control of Noncommunicable Diseases. WHO, 2013. http:// apps.who.int/iris/bitstream/10665/94384/ 1/9789241506236_eng.pdf?ua=1.

16 World Health Organization: Ending Childhood Obesity. WHO, 2016. http://apps.who. int/iris/bitstream/10665/204176/1/ 9789241510066_eng.pdf?ua $=1$ \&ua $=1$.

17 World Health Organization: Fiscal Policies for Diet and Prevention of Noncommunicable Diseases. WHO, 2016. http://apps.who. int/iris/bitstream/10665/250131/1/ 9789241511247-eng.pdf?ua=1.

18 World Health Organization: Development of a Draft Action Plan to Promote Physical Activity. WHO, 2018. http://www.who.int/ ncds/governance/physical_activity_plan/en/.

19 Christian P, Lee SE, Donahue Angel M, et al: Risk of childhood undernutrition related to small-for-gestational age and preterm birth in low- and middle-income countries. Int J Epidemiol 2013:42:1340-55.

20 Hales CN, Barker DJ: Type 2 (non-insulindependent) diabetes mellitus: the thrifty phenotype hypothesis. Diabetologia 1992;35: 595-601. 